\title{
LACKING RETIREMENT SAVINGS IS A REALITY FOR MANY 45+ TRANSGENDER AND GENDER EXPANSIVE ADULTS
}

There is a gap between the current financial situation and the retirement goals of many transgender and gender expansive adults

\section{$76 \%$}

will rely on Social Security

as a source of income

as they get older

\section{$91 \%$}

say having enough income or savings to retire is important to them

\section{$\mathbf{7 9} \%$}

feel that being able to stop working at the age they want is important

\section{$40 \%$}

vs. are not confident they will have enough money to live comfortably throughout their retirement years

\section{$58 \%$}

VS. will rely on part-time or full-time work, there is likely no full retirement for them

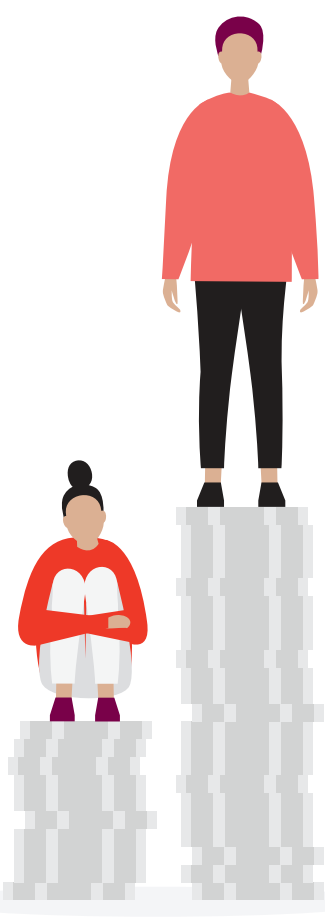

Low socioeconomic status for transgender and gender expansive adults makes economic security elusive
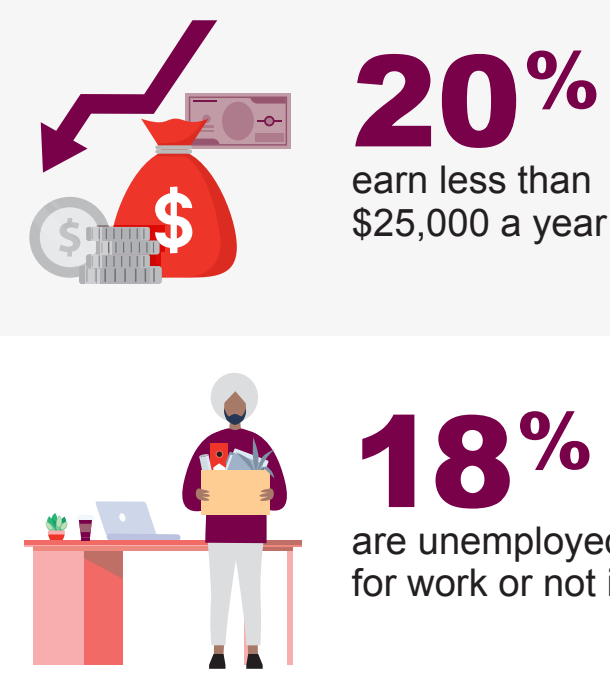

\section{$18 \%$}

are unemployed/looking

for work or not in the labor force
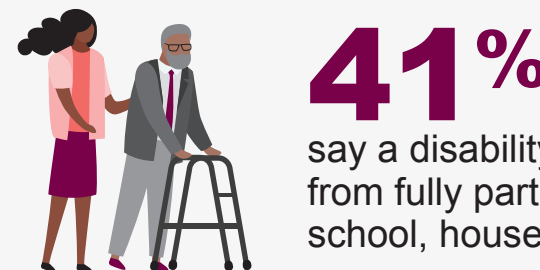

say a disability keeps them from fully participating at work, school, household or other activities

Lack of access to internet impedes financial progress including the inability to apply for jobs, work from home effectively or access gig economy work
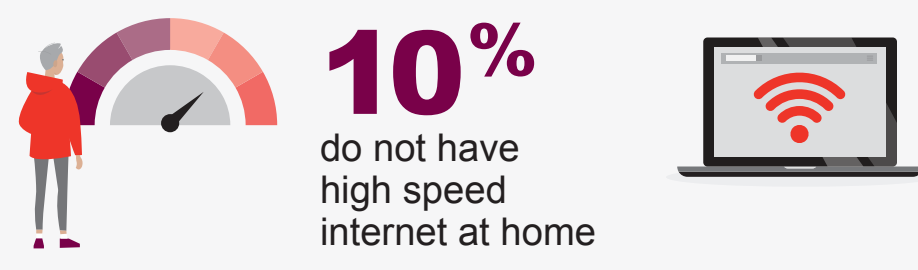

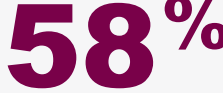

do not often have affordable internet services

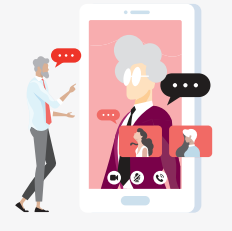

$40 \%$

do not often have internet services that were fast enough to do everything they need

Ideal Living Environments During Retirement

\section{$64 \%$}

say that an ideal environment for retirement would be to own a home

\section{$34 \%$}

want to live in a resort community known to be LGBTQ-friendly

\section{$40 \%$}

want to live in a place with lower cost of living

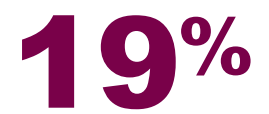

want to live in a LGBTQ-friendly assisted living community
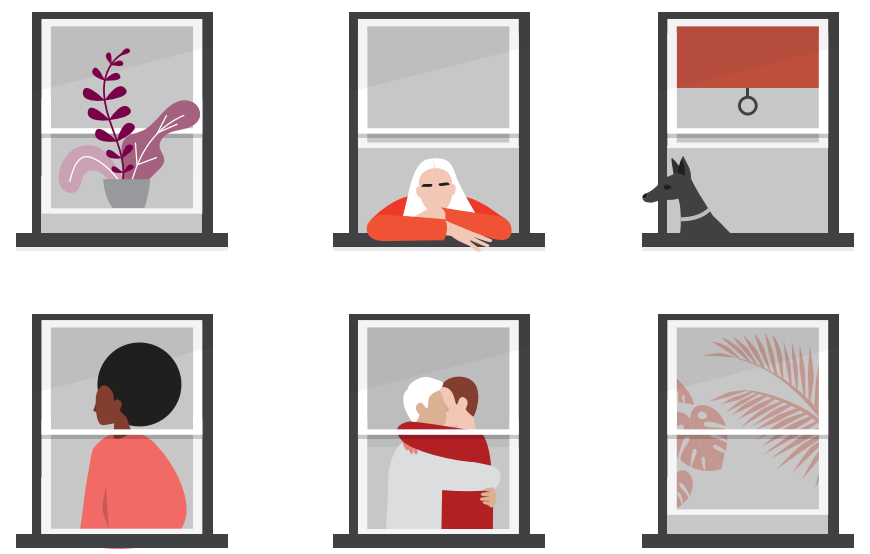